\title{
Transplantation of Autologous Fat, Stromal Vascular Fraction (SVF) Cell and Platelet Rich Plasma (PRP) for Cell Therapy of Atrophic Acne Scars: Clinical Evaluation and Biometric Assessment
}

\section{Mohammad Ali Nilforoushzadeh}

Tehran University of Medical Sciences

Maryam Heidari-Kharaji

Tehran University of Medical Sciences

Shiva Alavi

Tehran University of Medical Sciences

Mona Mahmoudbeyk

Tehran University of Medical Sciences

Maryam Nouri

Tehran University of Medical Sciences

Aisan Peyrovan

Tehran University of Medical Sciences

Sona Zare ( $\sim$ Sona.zaree@gmail.com )

University of Tehran https://orcid.org/0000-0003-4251-9014

\section{Research}

Keywords: Autologous fat, stromal vascular fraction (SVF), platelet rich plasma (PRP), acne scar, cell therapy, transplantation

Posted Date: August 18th, 2020

DOI: https://doi.org/10.21203/rs.3.rs-57442/v1

License: (c) (i) This work is licensed under a Creative Commons Attribution 4.0 International License. Read Full License

Version of Record: A version of this preprint was published at Journal of Cosmetic Dermatology on July 6th, 2021. See the published version at https://doi.org/10.1111/jocd.14333. 


\section{Abstract}

Background: Scarring is an unfortunate result of acne, because it causes psychological and cosmetic problems to patients. Unluckily no single treatment is suitable; using multiple methods may have better result. autologous fat and stromal vascular fraction (SVF) cells and their secretory factors can and enhance angiogenesis, collagen synthesis, and migration of fibroblasts therefore regenerate hurt tissues. Also, other treatments for acne scarring, like platelet rich plasma (PRP), induce the scare improvement. The aim of the study was to verify the effectiveness of transplantation of autologous fat, SVF cells and PRP as cell therapy technique on atrophic acne scars.

Methods: This study included 9 adult patients with atrophic acne scars on the face. All patients received transplantation of autologous fat, stromal vascular fraction (SVF) cells and PRP. The treatment outcome was measured by biometric assessment (Visioface 1000 D, Colorimeter, multi probe adapter Cutometer, Tewameter, Mexameter, and skin ultrasound imaging system), also patients' satisfaction was evaluated. The patients were followed 6 months after treatment.

Results: A significant improvement in the skin pores, spots, skin lightness and melanin content of the skin, skin elasticity and TEWL after 6 months of treatment. Also denser skin layers were observed both in the epidermis and dermis. Furthermore, $66.6 \%$ of the patients showed well satisfied after treatment.

Conclusion: Briefly, transplantation of autologous fat, SVF cells and PRP is an effective cell therapy for atrophic acne scars.

\section{Introduction}

Numerous skin disorders like scars or aging signs such as wrinkles may adversely affect the appearance and beauty of the skin. Scarring occurs as a natural process after a wound healing. However, the appearance of wounds is influenced by several factors. keloids and hypertrophic scars can treat by topical or injection application of corticosteroids [1]. However, there are some side effects like hypopigmentation and irreversible subcutaneous atrophy [2]. Scars are frequently treated by fewer invasive silicone dressing, but positive effects of them presently absence scientific evidence [3]. Laser therapy of scars is other option that may improve the appearance, however, laser technology has some limitation like skin discoloration [4, 5]. Finally, surgery can be a choice for treat overly obvious scars like dermabrasion, excision, subcision and skin grafting [6]. Nevertheless, aggressive surgical procedures are related to higher complications, leading to even larger scars with persistent contraction, which may worsen the condition [7]. By doing so, current scar treatments usually use ablative mechanisms that may have irreversible side effects. So, emphasizing the need for substitute techniques. Autologous fat injections have become very common in tissue regeneration over the past decade. Its good properties in regeneration and skin disorders have been reported in some studies [8-10]. Fat transplantation for repairing soft tissue defects have been applied for many years [1, 2]. Also in many study fat transplantation was used for acne scare treatment. $[11,12]$. Particularly, the study's results on restoring 
fat, bone, cartilage, nerve tissue, and muscle by adipose tissue-derived stem cells (ADSCs) have been informed $[3,10]$. It is reported that ADSCs can repair damaged tissue by their secretory factors that can induce angiogenesis, collagen synthesis and fibroblasts migration [11]. Also, recently, platelet rich plasma (PRP), alone or in combination with other techniques, is considered for acne scare treatment. A combination of PRP with other treatment options was performed in the treatment of many dermatological disorders such as acne scarring $[13,14]$. The PRP work way depends on the presence of protein, that increases the synthesis of collagen and elastic fibers lead to improves scar tissue and skin appearance $[15,16]$. The present study aimed to assess the efficacy and safety of transplantation of autologous fat, stromal vascular fraction (SVF) cells and PRP as cell therapy for atrophic acne scars treatment.

\section{Methods}

\section{Patients}

In this study, 9 patients with rolling acne scars were enrolled. Lesions were graded and classified by a board-certified dermatologist. Virus tests was done for all patients before treatment. Exclusion criteria were as follow: the existence of any active infectious diseases, patients who had received any procedure for acne scar treatment, patients with history of coagulopathy, skin cancer, oral steroid therapy, anticoagulant therapy, patients with systemic retinoid intake in the previous six months, patients who were pregnant or lactating were excluded from the study.

\section{Procedures and treatment monitoring}

\section{Liposuction surgical technique}

Taking into attention the individual characteristics of each patient, donor areas were selected mostly from hip, the lower abdomen, and thigh before preparing the appropriate design. On the day of surgery, lipoaspiration and injection of adipose was performed. In either general anesthesia or twilight anesthesia, anesthesia was induced by tumescent fluid $(500 \mathrm{~mL}$ normal saline with $15 \mathrm{ml}$ of $2 \%$ lidocaine [Pasteur institute of Iran] and $7 \mathrm{~mL}$ of bicarbonate and $1 \mathrm{mg}$ of epinephrine). After that, fat tissue was gathered with a Luer Lock syringe by utilizing a $2.4 \mathrm{~mm}$ cannula (Figure 1). The volume of fat that was collected from each patient was about $100 \mathrm{ml}$. The aspirated fat tissue was divided into two aliquots $(50 \mathrm{ml}) .50$ $\mathrm{ml}$ of lipoaspirated directly was grafted in the face and $50 \mathrm{ml}$ was used for the SVF cells isolation.

\section{SVF cells isolation}

To remove most red blood cells and leukocytes, the tissue was washed with phosphate-buffered saline (PBS) (Miltenyi Biotech, Cologne, Germany), then digested with type I collagenase (Worthington Biochemical Corp., Lakewood, USA) at $37^{\circ} \mathrm{C}, 20$ minutes under unbroken shaking. Solution of collagenase, final concentration of $0.2 \%$, was made just before use by adding collagenase powder to the Hanks balanced salt solution (HBSS) (Invitrogen, Carlsbad, USA). Digestion was prevented by washing 
with PBS (3 times). Floating and lysed adipocytes were waste and cells of the SVF were pelleted by 10 min centrifugation at $500 \mathrm{~g}$. The pellet was suspended in the HBSS and an erythrocyte lysis buffer (Sigma-Aldrich Corp, St. Louis, USA) was added and incubated 10 minutes at $37^{\circ} \mathrm{C}$. This cell suspension was centrifuged ( $500 \mathrm{~g}, 5 \mathrm{~min}$ ), and cells were counted and viability of cells were evaluated using Automatic cell counter (TC20 ${ }^{\mathrm{TM}}$ Automatic Cell Counter, Bio-Rad). Some of the suspension was subjected to flow cytometry (Partec, Görlitz, Germany) for evaluating cell surface markers and cell viability.

\section{Platelet-rich plasma preparation}

A sterile tube containing $1.5 \mathrm{~mL}$ anticoagulant (ACDA1) was arranged. Then, $10 \mathrm{~mL}$ of whole blood was drawn from each patient and collected in the sterile tube including $1 \mathrm{~mL}$ anticoagulant. In the next step the tube was centrifuged. The centrifugation process separates components of blood through their diverse specific gravities as follow; RBCs is the heaviest, after that WBCs, whereas platelets and plasma are the lightest. Centrifugation was performed in two-step; first step was a low level centrifugation to distinct whole plasma from platelets and red cells (at 900 RPM, 10-12 minutes). Then, all the supernatant plasma was aspirated by sterile angiocatheter and transferred from the tube in a sterile pure tube. The second step was high level centrifugation (2400 RPM, 8 minutes) to separated platelet-poor plasma from platelet-rich pellet; about $2 / 3$ of the supernatant platelet-poor plasma were wasted and the platelet-rich pellet was re-suspended in the remaining volume of plasma. The count of platelet in the developed PRP was expected to be 3 to 4 -fold more than in the whole blood. The obtained PRP was aspirated, and in order to platelets activation, $0.1 \mathrm{~mL}$ of calcium chloride was added per $0.9 \mathrm{~mL}$ of resulting PRP. The PRP of each patient was used to re-suspend the pellet of SVF for transplantation.

\section{Transplantation of aspirated fat tissueand SVF cells}

A topical anesthetic cream (EMLA containing 2.5\%lidocaine HCL and $2.5 \%$ prilocaine) was used for 45 minutes and afterward the area was sterilized via alcohol $70 \%$ and washed through normal saline to get finally dry skin surface. The aspirated fat tissue was injected (cannula with an 18-gauge blunt needle) subcutaneously into the skin of the face. Immediately, after aspirated fat tissue injection, the prepared SVF cells was re-suspend in the PRP and injected ( $1 \mathrm{~mL}$ syringe with a 30-gauge blunt needle) intradermal at the dose of $2 \times 10^{7}$ total for whole face of each patient.

\section{Outcome evaluation}

\section{SVF cells outcome}

The SVF cells counted by automatic cell counter. Also The SVF cells viability was evaluated by automatic cell counter. SVF cells surface markers and cell viability were evaluated by flow cytometry.

\section{Patients outcome}

\section{Biometric assessment}


Before and 6 months after treatment, Visioface (D1000 ck, Cologne, Germany) photographs of each patient were taken by a high-resolution digital camera. Biometric characteristics of the patients was evaluated by Visioface 1000 D, Colorimeter, multi probe adapter Cutometer (L parameter ), Tewameter, Mexameter, (all purchased from Courage + Khazaka Electronics, Cologne, Germany) and a skin ultrasound imaging system (TPM, Luneburg, Germany) to calculate the skin layers' thickness, the skin lightness, the skin elasticity by providing three parameters (R2, R5, R7), trans epidermal water loss (TEWL) and melanin content and the intensity of skin erythema before and after aspirated fat tissue and SVF cells transplantation, respectively. When the transplantation procedure was performed and the patients were followed up for 6 months.

\section{Patients' satisfaction}

The participants were requested to scale their subjective satisfaction of the treatment on a quartile grading scale (grade 1 = slightly satisfied, grade 2 = moderately satisfied, grade 3 = well satisfied).

\section{Statistical analysis:}

After testing for normal distribution of data by Kolmogorov-Smirnov test, the data were analyzed using paired-samples t-test through SPSS 14.0 (SPSS Inc, Chicago, Illinois, the United States). In all tests, P value $<0.05$ was considered statistically significant.

\section{Results}

\section{Automatic cell counter}

\section{The viability and count of SVF cells harvest from fat tissue}

The nucleated cell harvest was counted by the automatic cell counter. Also the cell viability of the cell was assessed. The results were shown in the Table 1 for each patients. The results showed that the mean of yield cell was $22 \pm 1.5 \times 10^{6}$ cells $/ \mathrm{mL}$ of aspirated fat tissue and the mean of viability was $94.1 \pm 2.5$ (Table 1). 
Table 1

Count and viability of SVF after evaluation by the automatic cell counter.

\begin{tabular}{|llll|}
\hline Sample No. & SVF count & SVF viability $(\%)$ & Total volume $(\mathrm{mL})$ \\
\hline 1 & $24 \times 10^{6}$ & 92 & 80 \\
\hline 2 & $28 \times 10^{6}$ & 93 & 80 \\
\hline 3 & $22 \times 10^{6}$ & 95 & 80 \\
\hline 4 & $25 \times 10^{6}$ & 94 & 80 \\
\hline 5 & $20 \times 10^{6}$ & 93 & 80 \\
\hline 6 & $19 \times 10^{6}$ & 98 & 80 \\
\hline 7 & $21 \times 10^{6}$ & 90 & 80 \\
\hline 8 & $20 \times 10^{6}$ & 97 & 80 \\
\hline 9 & $23 \times 10^{6}$ & 95 & 80 \\
\hline
\end{tabular}

\section{Svf Cells Flow Cytometric Analysis}

\section{The viability of nucleated SVF cells}

The viability of nucleated SVF cells isolated from all patients was evaluated by flow cytometry (Fig. 2). According to the flow cytometry results the mean viability of cells was about $97 \pm 1.2 \%$.

\section{The Surface Markers Of Nucleated Svf Cells}

The properties of SVF cells were investigated by flow cytometry (Fig. 3). The examination of the fresh isolated SVF cells surface markers displayed the expression of endothelial markers included CD146, CD31, and CD34. Moreover, the expressions of the mesenchymal markers comprising CD44, CD73, CD90, and CD105 were determined. It should be noted that CD44 is a hyaluronic acid receptor which contributes in the dermal thickness and can be used for the molecular cues of skin rejuvenation assessment. Also, CD14, CD15, and CD45 as hematopoietic stem cell markers were found in the SVF isolated cell population. The CD56, natural killer cell marker, was expressed as well.

\section{Biometric Characteristic}


The biometric data of the patients are shown in the Table 2. Briefly, the size and number of skin pores and spots were reduced after treatment (Figs. 4 and 5). The Visioface results displayed that the transplantation can significantly decrease the number of skin pores and skin spots, and the percentages of change in the number of fine pores, large pores and spots were $43.01 \pm 11.14,47.37 \pm 14.13$ and 41.98 \pm 10.19 , respectively $(P<0.001$; Table 2$)$. The colorimeter results showed the skin lightness before and after treatment was $11.46 \pm 2.64$ and $15.94 \pm 2.86$ (Table 2). There was a significant change in skin lightness before and after treatment Fig. $6, \mathrm{P}<0.05$ and the percentage of change in the skin lightness after treatment was $36.79 \pm 10.80$, (Table 2 ) $P<0.05$. Similarly, the results of Cutometer showed the significantly increase in the elasticity of the skin and the R2, R5 and R7 percentage of changes were (33.12 \pm 8.28$),(25.41 \pm 11.38)$ and $(36.09 \pm 13.16)$ before and after treatment $(P<0.001)$. Also the results showed the treatment cause decreased in TEWL. The significant changes in melanin content of the patients were seen and the changes in the melanin content before and after treatment were $(295.85 \pm$ $80.98)$ and $(200.43 \pm 40.45)$ respectively and the percentage of melanin changes was $(32.21 \pm 10.72)$. There were not significant changes in erythema intensity before and after treatment (Table 2). Also, the results of skin ultrasonography exhibited denser skin layers both in the epidermis and dermis (Fig. 6; Table 2). According to the Table 2, a significant increase was detected in the density and thickness of the epidermis and dermis before and after treatment and the percentage of change in the density and thickness of the epidermis and dermis was $(56.01 \pm 30.41),(48.58 \pm 50.12)$ and $(58.04 \pm 20.39),(43.11 \pm$ $29.50)$ respectively $(P<0.001)$. 
Table 2

Comparing biometric characteristics of the patient's skin before and 6 months after the treatment.

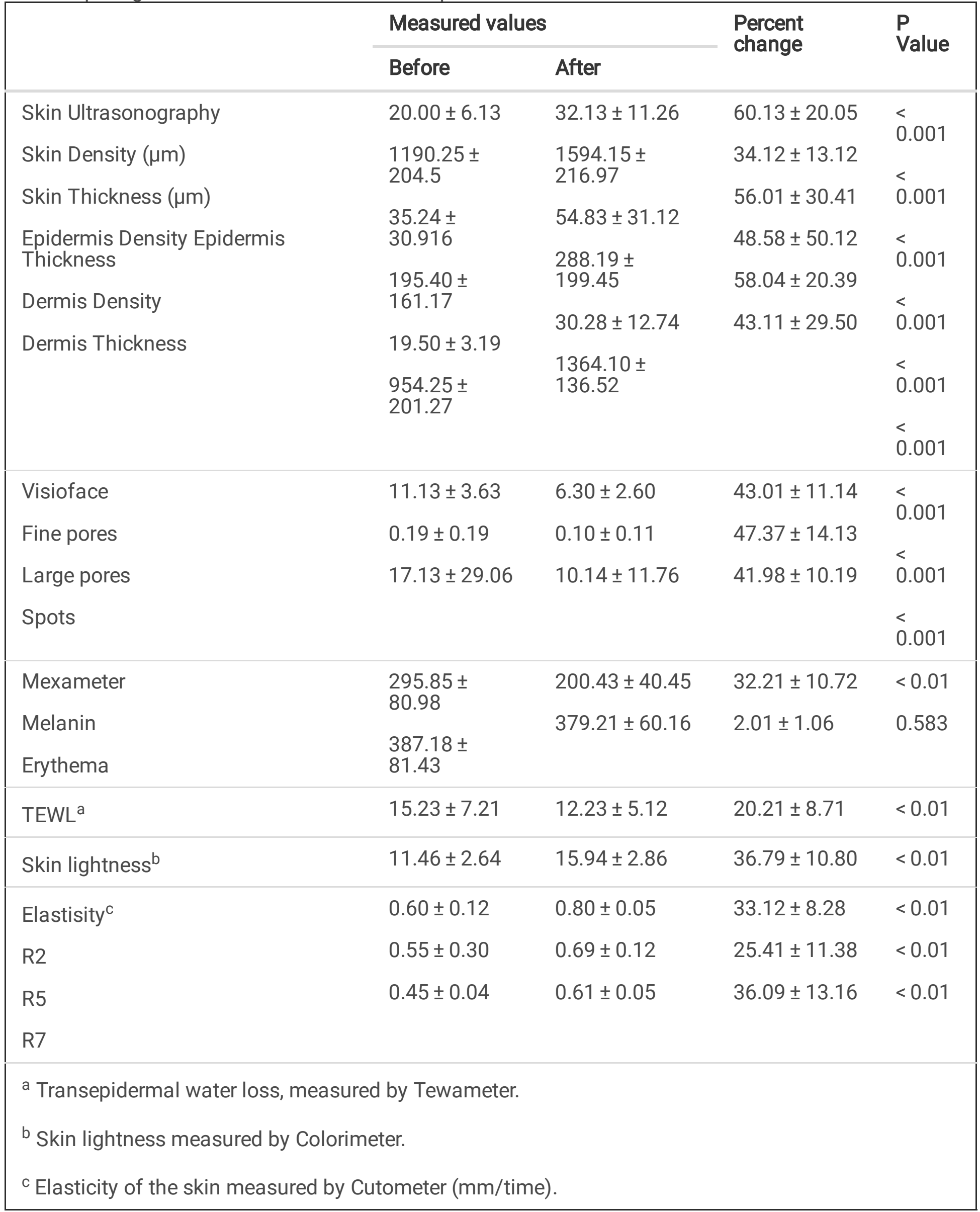




\section{Patients' Satisfaction Results}

The mean score of patients' satisfaction was shown in the Table 3. $22.3 \%$ of the patients showed moderately satisfied and $66.6 \%$ showed well satisfied after treatment.

Table 3

Patient satisfaction six months after treatment. The $\mathrm{P}<$ 0.05 was considered as statistically significant in all the tests

\begin{tabular}{|llll|}
\hline Valid & Frequency & Percent & P value \\
\hline No satisfaction & 0 & $0 \%$ & 0.01 \\
Slightly satisfied & 1 & 11.1 & \\
Moderately satisfied & 2 & 22.3 & \\
Well Satisfied & 6 & 66.6 & \\
Total & 9 & 100 & \\
\hline
\end{tabular}

\section{Discussion}

Acne is a common disorder that affects about $80 \%$ of young and $5 \%$ of adult's people [17]. One of the major mechanisms that is involved in the atrophic acne scars pathogenesis is collagen loss. So, stimulation of collagen production is the goal of several methods that have been proposed for the acne scar treatment [18]. Fat transplantation has been displayed to have beneficial effects on acne scars, which were primarily treated for volume loss. It seems, fat transplantation can repair collagen organization and reduce the fibrotic response to radiation and it is most likely induce improvement by many growth factors already present in lipoaspirate, which helps regenerating and remodeling of skin and scars. Also, studies indicate that tissue remodeling, the formation of fresh and new blood vessels, and inflammatory responses are possible causes of scars treatment in fat transplantation [11]. Because of biocompatible and not immunogenic properties of the adipose tissue, it is an ideal transplant for a patient with acne scar. In addition, it is easy to yield with minimal side effects in the donor site. The first autologous fat transfer for facial volume loss was reported in 1893, when fat was applied to fill subcutaneous defects [19]. In 1912, the correction in retracted scar after mastectomy was reported by fat injections [12]. However, in recent times, the method of fat harvesting and injection has been modified and significantly improved, so it takes better results. In some studies, the plasticity and elasticity of scar tissue was increased, which was also observed microscopically in scar sample after lipofilling treatment $[20,21]$. In previous clinical study, regenerative effects of adipose tissue in the dermis and subcutaneous tissue was informed $[22,23]$. Fat transplantation has been applied in a diversity of disorders relating volume loss like panfacial global subcutaneous atrophy secondary to intrinsic aging or trauma [24].

Furthermore, stem cells have many unique properties that make them theoretically have great potential in managing a large number of diseases [25]. Some of these features include unlimited proliferation 
capability and plasticity [26]. It seemed recent research have shown interested to use of stem cell injection in acne scars treatment [27]. There is mutual agreement that autologous adipose tissue-derived stem cells (ADSCs) are multi- and pluripotent [28-30]. ADSCs are found in large amounts in the stromal vascular fraction (SVF) of adipose tissue [31]. ADSCs and their secretory factors can induce angiogenesis, collagen synthesis and fibroblasts migration therefore regenerate impaired tissues [11]. In the Zhang et al. study the effect of intralesionally injection of adipose tissue derived stem cells into rabbit ears are evaluated and reduction in the hypertrophic scarring formation was reported by enhancing collagen deposition [32]. In Abou Eitta study, it is shown that ADSCs is more effective than fractional carbon dioxide laser in the treatment of acne scars [11]. The efficacy of ASCs on scar appearance improvement has been studied in some studies. In the study of Lee et al. it is reported that SVF cells injections can enhance tissue regeneration via contributing stem cells and growth factors to improve the results in tissue grafts or scar revisions [33]. Lee and collogues evaluated the effect of combination of adipose tissue with SVF cells on the facial skin disorder and they declare Facial Soft Tissue significantly increase in the facial area grafted with adipose tissue in combination with SVF cells in compare to adipose tissue without SVF cells [34]. Also Recently, platelet-rich plasma (PRP) used alone or in combination with other therapy as an effective option for the atrophic acne scars treatment $[14,35]$. The PRP work way depends on the presence of protein, that increases the synthesis of collagen and elastic fibers lead to improves scar tissue and skin appearance $[15,16]$. So in recent study we used combination of transplantation of autologous fat, SVF cells and PRP for atrophic acne scars treatment. In the study of Gentill et al., the effect of SVF cells and PRP the face scars were evaluated and they reported that the patients showed $69 \%$ maintenance of contour restoring after fat grafting and PRP treatment [36]. In the Pradeep V Mahajan study. Regenerative Medicine Using Platelet Rich Plasma and Stem Cells in Atrophic Acne Scars: A Case Report [37]. Our results showed that transplantation of autologous fat and SVF cells and PRP is a good technique for treatment of atrophic acne scars with significantly increase in skin lightness and melanin content of the skin. Also the elasticity of the skin was increased. Oure results indicated that number of skin fine pores, large pores and spots were significantly decrease after treatment. Briefly transplantation of autologous fat, SVF cells and PRP is very promising strategy based on cell therapy for atrophic acne scars improvement with a minimal side effect.

\section{Conclusion}

transplantation of autologous fat, SVF cells and PRP is very promising strategy based on cell therapy for atrophic acne scars improvement by repair the collagen organization, increase elastic fibers and reduce the fibrotic response to radiation and it is most likely induce improvement by many growth factors, which helps regenerating and remodeling of skin and scars. Also, tissue remodeling, the formation of fresh and new blood vessels, and inflammatory responses are possible causes of scars treatment in this technique.

\section{Declarations}

\section{Abbreviations}


SVF

stromal vascular fraction

PRP

platelet rich plasma

PBS

phosphate-buffered saline

ADSCs

autologous adipose tissue-derived stem cells

HBSS

Hanks balanced salt solution

RBC

Red Blood Cells

WBC

Wight Blood Cells

\section{Declarations}

\section{Ethical Approval and Consent to participate}

The authors stat that the patients have given their informed consent for participate, the photos and details.

\section{Consent for publication}

The authors stat that the patients have given their informed consent for the photos, details and publication.

\section{Availability of data and material}

Data available on request from the authors

\section{Funding}

No funding

\section{Authors' contributions}

Mohammad Ali Nilforoushzadeh: Supervisor, Maryam Heidari-Kharaji: Manuscript writing and data analysis, Shiva Alavi: clinical methods, Mona Mahmoudbeyk: Collecting data, Maryam Nouri: Biometric characteristics evaluation, Aisan Peyrovan: Collecting data, Sona Zare: PRP preparation and cell evaluation.

\section{Competing interests}


The authors declare no conflicts of interest.

\section{Acknowledgements}

We appreciatively acknowledge the colleagues and staffs in Skin and Stem Cell Research Center, Tehran University of Medical Sciences, Tehran, Iran.

\section{References}

1. Illouz Y-G. The fat cell "graft": a new technique to fill depressions. Plastic reconstructive surgery. 1986;78(1):122.

2. Kim SB, Kim DW, Yoon ES. Facial fat injection: long-term follow-up results. Journal of the Korean Society for Aesthetic Plastic Surgery. 2010;16(1):35-40.

3. Zuk PA, et al. Multilineage cells from human adipose tissue: implications for cell-based therapies. Tissue engineering. 2001;7(2):211-28.

4. Dhar $\mathrm{S}$, et al. Long-term maintenance of neuronally differentiated human adipose tissue-derived stem cells. Tissue engineering. 2007;13(11):2625-32.

5. Nilforoushzadeh MA, et al., Fractional carbon dioxide laser and its combination with subcision in improving atrophic acne scars. Advanced biomedical research, 2017. 6.

6. Nilforoushzadeh MA, et al. Comparing cannula-based subcision with the common needle method: A clinical trial. Skin Research Technology. 2020;26(1):39-44.

7. Yoon E, et al. In vivo osteogenic potential of human adipose-derived stem cells/poly lactide-coglycolic acid constructs for bone regeneration in a rat critical-sized calvarial defect model. Tissue engineering. 2007;13(3):619-27.

8. Nilforoushzadeh MA, Lotfi E, Heidari-Kharaji M, Autologous adipose transplantation an effective method to treat alopecia after trauma: a case report. Clinical, Cosmetic and Investigational Dermatology, 2019. 12: p. 647.

9. Jeong T-W, et al. Treatment of Phalangeal Bone Defect Using Autologous Stromal Vascular Fraction from Lipoaspirated Tissue. Archives of Plastic Surgery. 2011;38(4):438-44.

10. Poloni $A$, et al. Human dedifferentiated adipocytes show similar properties to bone marrow-derived mesenchymal stem cells. Stem Cells. 2012;30(5):965-74.

11. Abou Eitta RS, et al. Evaluation of autologous adipose-derived stem cells vs. fractional carbon dioxide laser in the treatment of post acne scars: a split-face study. International journal of dermatology. 2019;58(10):1212-22.

12. Holländer E, Die kosmetische chirurgie. 1912: Veit.

13. Kang JS, et al. The effect of CD34 + cell-containing autologous platelet-rich plasma injection on pattern hair loss: a preliminary study. J Eur Acad Dermatol Venereol. 2014;28(1):72-9.

14. Chawla S. Split face comparative study of microneedling with PRP versus microneedling with vitamin $\mathrm{C}$ in treating atrophic post acne scars. Journal of cutaneous aesthetic surgery. 
2014;7(4):209.

15. Kang BK, et al. Infraorbital rejuvenation using PRP (platelet-rich plasma): A prospective, randomized, split-face trial. J Am Acad Dermatol. 2013;68:24.

16. Abdel Aal AM, et al. Evaluation of autologous platelet-rich plasma plus ablative carbon dioxide fractional laser in the treatment of acne scars. Journal of Cosmetic Laser Therapy. 2018;20(2):10613.

17. El-Domyati $\mathrm{M}$, et al. Microneedling therapy for atrophic acne scars: an objective evaluation. J Clin Aesthetic Dermatol. 2015;8(7):36.

18. Gonzalez MJ, et al., Treatment of acne scars using the plasma skin regeneration (PSR) system. Lasers in Surgery and Medicine: The Official Journal of the American Society for Laser Medicine and Surgery, 2008. 40(2): p. 124-127.

19. Neuber F. Fettransplantation. Chir Kongr Verhandl Dsch Gesellch Chir, 1893. 22: p. 66.

20. Bruno A, et al. Burn scar lipofilling: immunohistochemical and clinical outcomes. Journal of Craniofacial Surgery. 2013;24(5):1806-14.

21. Pallua $\mathrm{N}$, et al. Improvement of facial scar appearance and microcirculation by autologous lipofilling. Journal of Plastic Reconstructive Aesthetic Surgery. 2014;67(8):1033-7.

22. Rigotti G, et al. Clinical treatment of radiotherapy tissue damage by lipoaspirate transplant: a healing process mediated by adipose-derived adult stem cells. Plastic reconstructive surgery. 2007;119(5):1409-22.

23. Klinger $M$, et al. Regenerative approach to scars, ulcers and related problems with fat grafting. Clin Plast Surg. 2015;42(3):345-52.

24. Donofrio LM. Structural autologous lipoaugmentation: a pan-facial technique. Dermatologic surgery. 2000;26(12):1129-34.

25. Strauer B, Schannwell C, Brehm M. Therapeutic potentials of stem cells in cardiac diseases Minerva cardioangiologica. 2009;57(2):249.

26. Takahashi $\mathrm{K}$, et al. Induction of pluripotent stem cells from adult human fibroblasts by defined factors. cell. 2007;131(5):861-72.

27. Wolfram D, et al. Hypertrophic scars and keloids-a review of their pathophysiology, risk factors, and therapeutic management. Dermatologic surgery. 2009;35(2):171-81.

28. Gutiérrez-Fernández $\mathrm{M}$, et al. Adipose tissue-derived mesenchymal stem cells as a strategy to improve recovery after stroke. Expert Opin Biol Ther. 2015;15(6):873-81.

29. Richardson SM, et al. Mesenchymal stem cells in regenerative medicine: focus on articular cartilage and intervertebral disc regeneration. Methods. 2016;99:69-80.

30. Suzuki E, et al. Adipose tissue-derived stem cells as a therapeutic tool for cardiovascular disease. World J Cardiol. 2015;7(8):454.

31. Zuk PA, et al. Human adipose tissue is a source of multipotent stem cells. Molecular biology of the cell. 2002;13(12):4279-95. 
32. Zhang Q, et al. Intralesional injection of adipose-derived stem cells reduces hypertrophic scarring in a rabbit ear model. Stem Cell Res Ther. 2015;6(1):145.

33. Lee JW, et al. Clinical impact of highly condensed stromal vascular fraction injection in surgical management of depressed and contracted scars. Aesthetic Plast Surg. 2018;42(6):1689-98.

34. Lee SK, et al. Facial soft tissue augmentation using autologous fat mixed with stromal vascular fraction. Archives of plastic surgery. 2012;39(5):534.

35. Gawdat $\mathrm{HI}$, et al. Autologous platelet rich plasma: topical versus intradermal after fractional ablative carbon dioxide laser treatment of atrophic acne scars. Dermatol Surg. 2014;40(2):152-61.

36. Gentile P, et al. Adipose-derived stromal vascular fraction cells and platelet-rich plasma: basic and clinical evaluation for cell-based therapies in patients with scars on the face. Journal of Craniofacial Surgery. 2014;25(1):267-72.

37. Mahajan $\mathrm{P}$, et al. Regenerative medicine using platelet rich plasma and stem cells in atrophic acne scars: a case report. J Cosmo Trichol. 2017;3(120):2.

\section{Figures}

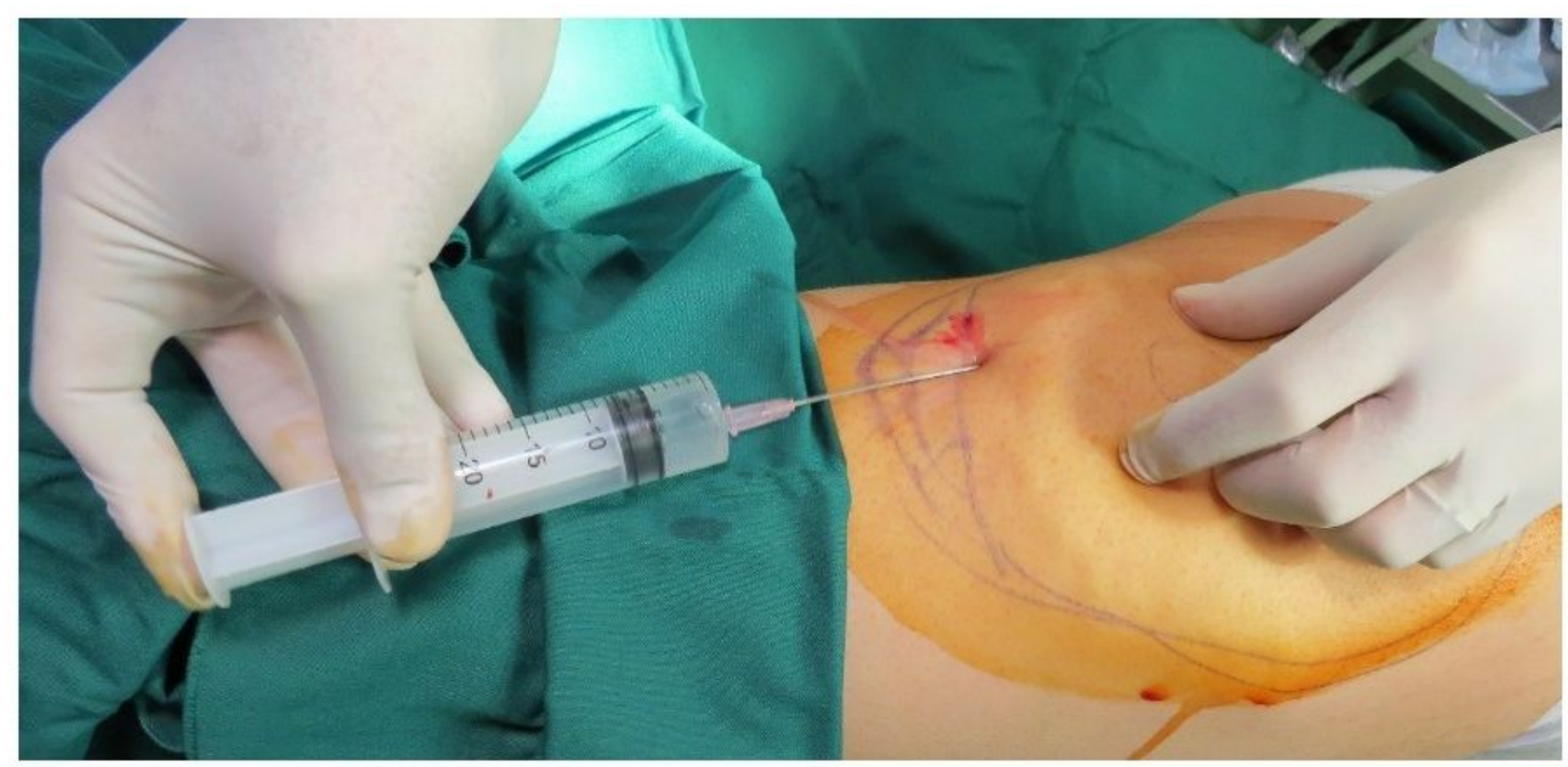

\section{Figure 1}




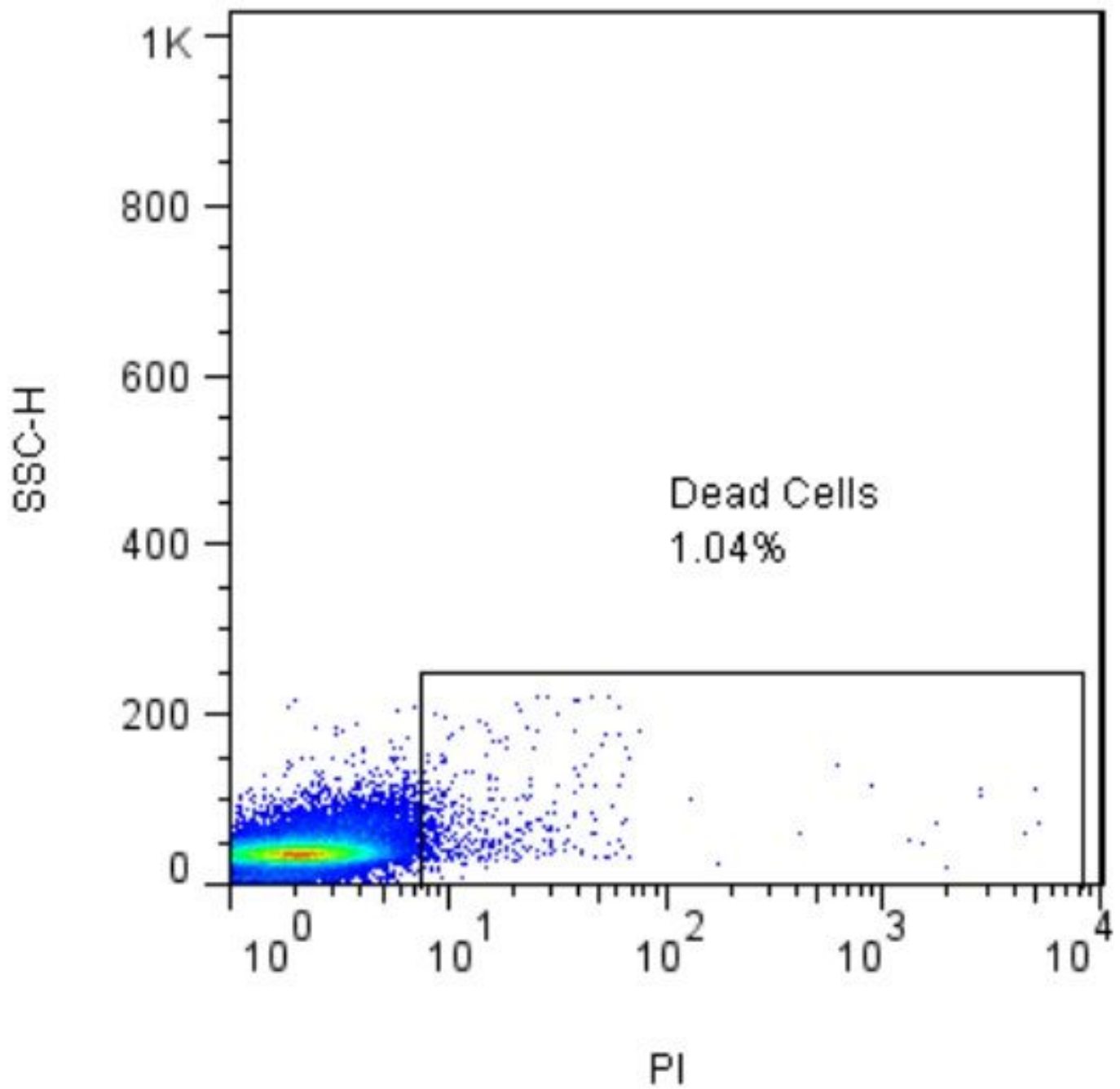

SVF-T.060

FSC-H, SSC-H subset

42497

Figure 2 


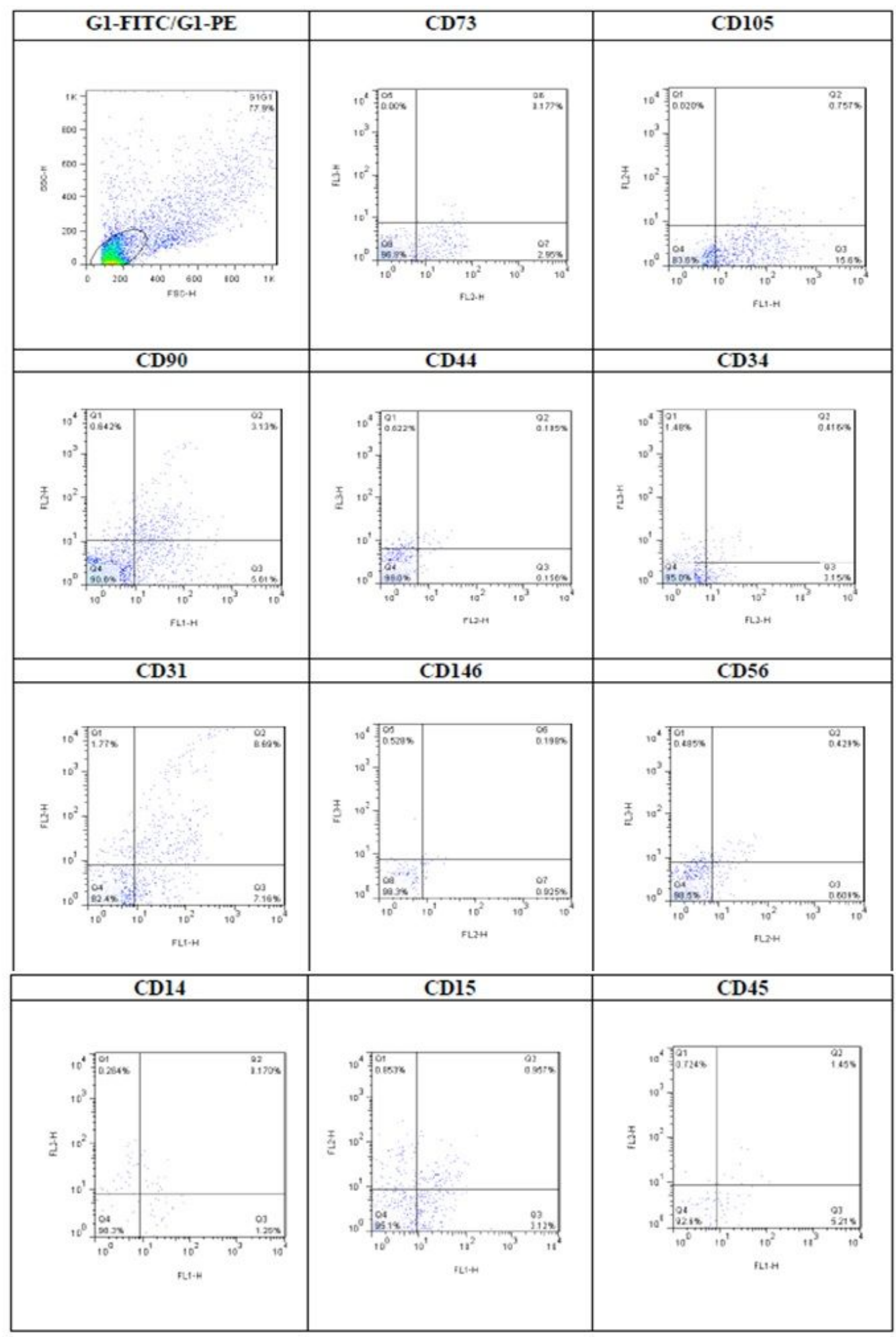

Figure 3 


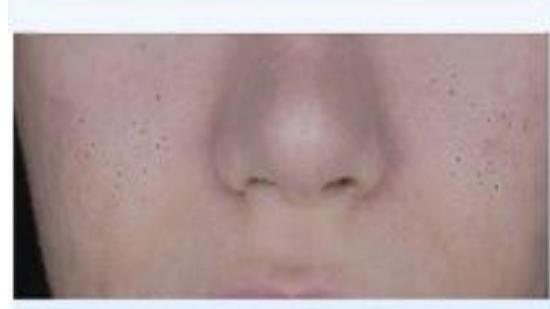

\begin{tabular}{|c|c|c|}
\hline Image 1 & Fine & Large \\
\hline Courk & 68 & 6 \\
\hline Anea & $1,95000 \mathrm{cox}$ & $425 p \mathrm{x}$ \\
\hline \% Area & $0.25 \%$ & $0.05 \%$ \\
\hline D.Area & \multicolumn{2}{|c|}{$32 p x$} \\
\hline
\end{tabular}

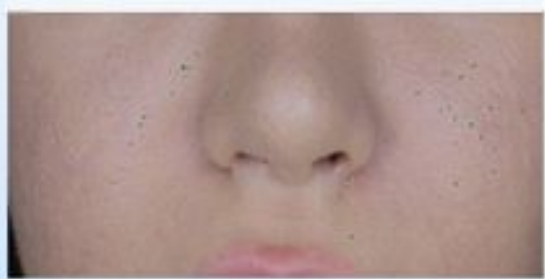

Before

\begin{tabular}{|c|c|c|}
\cline { 2 - 3 } \multicolumn{1}{c|}{ Image 2 } & Fine & Large \\
\hline Courk & 52 & 6 \\
\hline Asea & 1,565 pox & $382 \mathrm{px}$ \\
\hline \%.Area & $0.20 \%$ & $0.05 \%$ \\
\hline D.Area & \multicolumn{2}{|c|}{$33 . \mathrm{pw}$} \\
\cline { 2 - 3 }
\end{tabular}

After

Figure 4
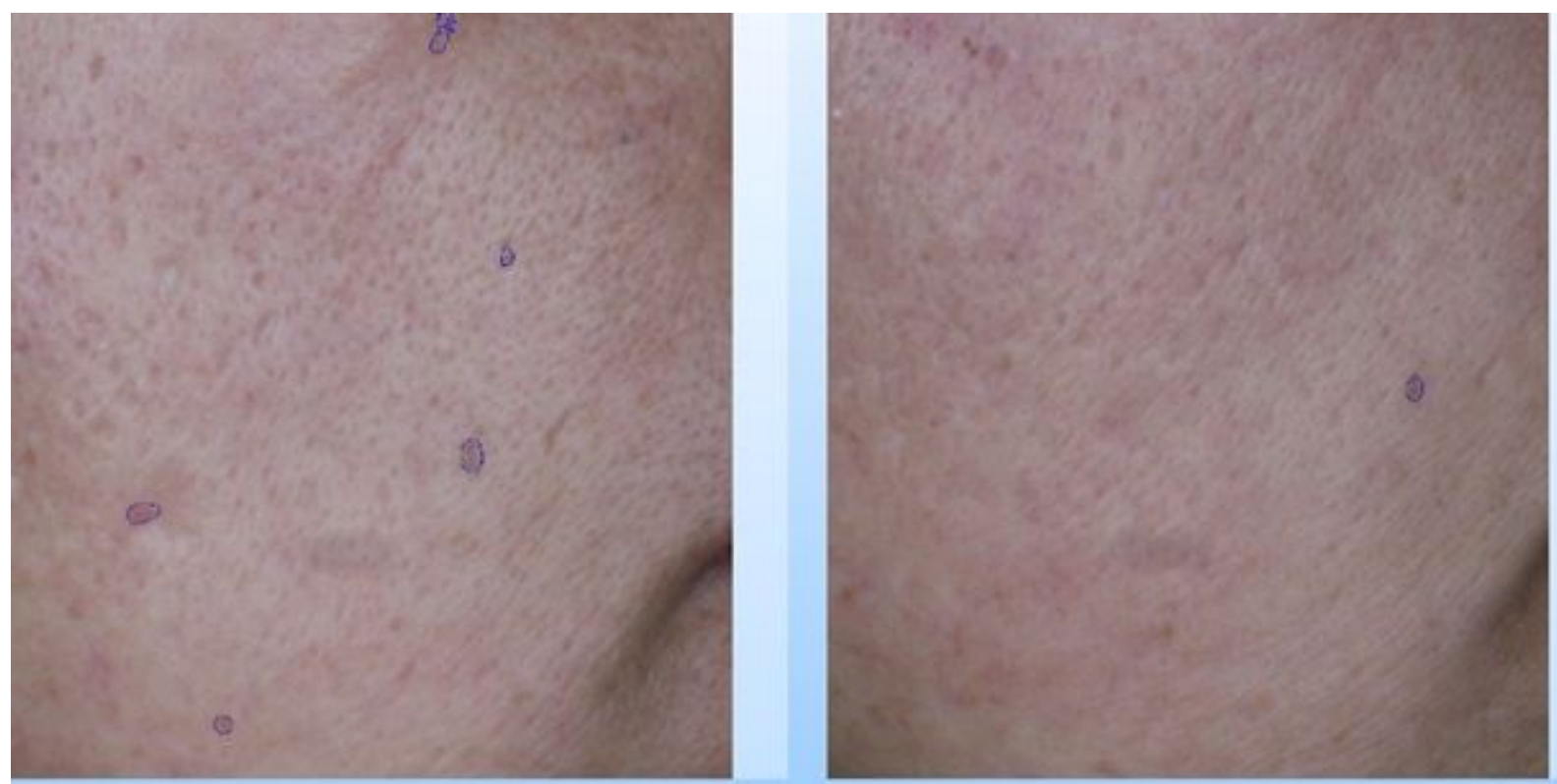

Before

\begin{tabular}{|c|c|}
\hline Court & 5 \\
\hline Area & $1,823 \mathrm{pos}$ \\
\hline XArea & $0.38 \%$ \\
\hline
\end{tabular}

After

\begin{tabular}{c|c|}
\multicolumn{2}{|l|}{ Image 2 } \\
\cline { 2 - 2 } Count & 1 \\
\hline Asea & $282 \mathrm{px}$ \\
\hline *.Acea & $0.06 \%$ \\
\hline
\end{tabular}

Figure 5 


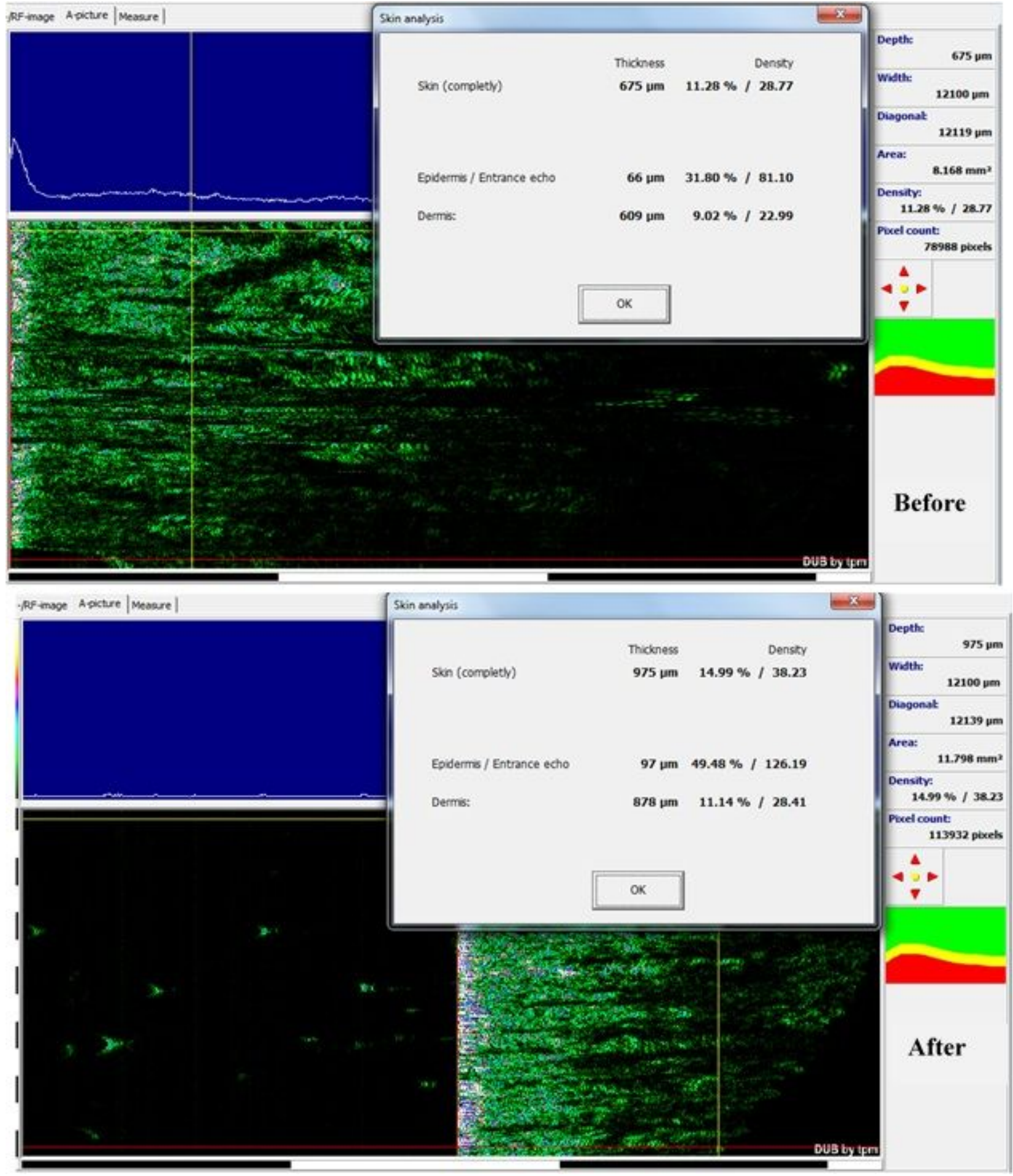

Figure 6 